\title{
O SUJEITO “BIOGRÁFICO” NA FICÇÃO DE TEZZA
}

\author{
THE "BIOGRAPHICAL" SUBJECT IN TEZZA'S FICTION
}

\author{
Recebido: 11/10/2021
}

Aprovado: $11 / 11 / 2021$

DOI: $10.18817 /$ rlj.v5i2.2669

\author{
Publicado: 22/12/2021
}

Cecília Guedes Borges de Araújo ${ }^{1}$ Orcid ID: $\frac{\text { http://orcid.org/0000-0002-9082-2168 }}{\text { Fabrício Flores Fernandes }}$

Orcid ID: https://orcid.org/0000-0001-6922-2558

\begin{abstract}
Resumo: Neste artigo, propomos uma discussão acerca da biografia, da história e da ficção presentes em O filho eterno (2011), do escritor catarinense Cristovão Tezza. Há na obra a construção de um mundo ficcional que se vale das experiências de vida como fonte primeira de inspiração, mas que, ao configurá-lo através da linguagem, transcende-o, transforma-o. O romance tematiza a história de um pai que descobre que o filho tem síndrome de Down, na década de 80, e apresenta movimentos pendulares do narrador enquanto sujeito e analista da narrativa. Investiga-se aqui a hipótese de que há na construção ficcional tezziana reflexões do sujeito pai, enquanto narrador e personagem, manifestando, assim, na linguagem, a dificuldade em delimitar uma fronteira entre a ficção e a não-fiç̧ão na obra. Para tanto, apoiamo-nos nas reflexões acerca dos problemas de história, ficção e biografia discutidos e contextualizados com base nas análises dos trechos da obra e fundamentados por Arfuch (2010), Bosi (2013), Chiappini (2000), Gagnebin (2001), Lejeune (2014) e Saramago (2013).
\end{abstract}

Palavras-chave: Literatura brasileira contemporânea. Ficção. Subjetividade. O filho eterno.

Abstract: In this article, we propose a discussion about biography, history and fiction, theoretical issues raised in O filho eterno (2011), by Cristovão Tezza. There is in the work the construction of a fictional world that uses life experiences as a primary source of inspiration, but that, by configuring it through language, transcends it, transforms it. The novel focuses on the story of a father who discovers that his son has Down syndrome, in the $80 \mathrm{~s}$, and presents pendular movements of the narrator as a subject and narrative analyst. Here, we investigate the hypothesis that there are reflections of the father subject in the fictional construction of Tezza, as narrator and character, thus manifesting, in language, the difficulty in delimiting a boundary between fiction and non-fiction in the work. Therefore, we rely on reflections on the problems of history, fiction and biography discussed and contextualized based on the analysis of excerpts from the work and supported by Bosi (2013), Gagnebin (2001), Lejeune (2014) and others.

Keywords: Contemporary Brazilian Literature. Fiction. Subjectivity. O filho eterno.

\section{A construção do "real" na ficção}

\footnotetext{
1 Professora do quadro provisório do curso de Letras Português (Literatura) da Universidade Estadual do Maranhão - UEMA (Centro de Estudos de Barra do Corda - CESBAC). Doutoranda em Estudos de Linguagens (Literatura, Estudos Comparados e Interartes) pela Universidade Federal de Mato Grosso do Sul - UFMS, Mestra em Letras (Literatura, Memória e Cultura), Especialista em Estudos Linguísticos e Literários e Graduada em Letras Português pela Universidade Estadual do Piauí - UESPI. E-mail: ceciliaguedesba@gmail.com

2 Possui graduação em Letras Português pelo Centro Universitário Franciscano (2000), mestrado em Letras pela Universidade Federal de Santa Maria (2003), doutorado em Teoria e História Literária pela Universidade Estadual de Campinas (2008) e pós-doutorado pela Universidade Federal do Piauí (2009). Atualmente é Professor Adjunto IV da Universidade Estadual do Piauí e Membro de corpo editorial da Revista Desenredos. Tem experiência na área de Letras, com ênfase em Teoria Literária. Atuando principalmente nos seguintes temas: Testemunho, Teoria Literária, História Literária, Ditadura militar. E-mail: fabricioflores@gmail.com
} 
A questão do grau de subjetividade da narrativa tem sido muito discutida na crítica e na teoria literárias, uma vez que há uma linha tênue entre a ficção e um discurso que se reconhece como fidedigno. Tem crescido muito a quantidade de obras sobre as experiências pessoais do autor ou até mesmo biografias escritas por outras pessoas sobre determinadas personalidades.

O filho eterno, de Cristovão Tezza, é um romance brasileiro contemporâneo, publicado em 2011, que atua nos campos da fiç̧ão e, sobretudo, da biografia. O ponto-chave da questão é que se trata de experiências pessoais que são narradas como ficção. Este artigo não busca provar se Tezza escreveu uma ficção ou não, mas especular sobre em que linha atua sua escrita e se é possível definir a fronteira entre "mundo real" e criação, ou ainda, como afirma Lejeune (2014), se há criação em relatar uma experiência pessoal.

A propósito, quais os limites da ficção na construção de um mundo ficcional que se vale do "mundo real"? Até que ponto é verdade e até que ponto é inventado? É possível determinar esse limite entre a biografia e a ficção? A partir desses questionamentos, Victoria Saramago, crítica literária contemporânea, em seu estudo O filho eterno, o duplo do pai: o filho e a ficção de Cristovão Tezza, no qual analisa a obra à luz da teoria de Lejeune (2014), faz a seguinte afirmativa, sobre considerá-la uma obra de ficção ou autobiográfica:

\begin{abstract}
O interessante aqui, ao lado da óbvia negação de qualquer compromisso ou pacto com a referencialidade, é que o recurso ao narrador em terceira pessoa é evocado como um modo de aproximação do discurso ficcional. A essa falta de identidade entre narrador e protagonista soma-se outra que, como vimos, será fatal para qualquer tentativa de considerar O Filho Eterno uma autobiografia na acepção proposta por Lejeune. Trata-se da falta de homonímia entre o autor e o protagonista - ou a melhor, a sua não afirmação. Pois não é que o protagonista apresente um nome fictício: ele não apresenta nome algum. (SARAMAGO, 2013, p. 64 - 65)
\end{abstract}

A primeira consideração da crítica deve-se ao fato de que o autor e a personagem central do romance - o pai - não têm o mesmo nome, o que problematiza a possibilidade de a obra ser identificada como autobiográfica, segundo a teoria de Lejeune (2014). Mais interessante ainda é que, além de não serem homônimos, a personagem não tem um nome, isto é, o escritor procura com isso desligar de si mesmo, enquanto pessoa "real", e passa a ser personagem da própria criação. Ele é obra de si mesmo, assume o papel de analista e, ao mesmo 
tempo, "paciente", fazendo a sua autoanálise por detrás, como se estivesse distante de si.

Esse recurso é utilizado, também, na área da psicanálise, em que o autor cria uma obra com elementos de sua vida, não necessariamente tudo, e inventa outros, compondo a ficção com uma personagem com características semelhantes às suas. No entanto, não quer dizer que deixa de ser ficção porque existam características pessoais e também não passa a ser autobiografia por apresentar relatos que coincidam com a vida do autor. Na obra, o narrador menciona obras de Tezza que, por sinal, têm o mesmo nome do personagem pai, deixando que o leitor desconfie se tratar da mesma pessoa:

Começou há pouco a escrever outro romance, Ensaio da paixão, em que ele imagina - passará a limpo sua vida. E a dos outros, com a língua da sátira. Ninguém se salvará. Três capítulos prontos. É um livro alegre, ele supõe. Eu preciso começar, de uma vez por todas, ele diz a ele mesmo, e só escrevendo saberá quem é. Assim espera. São coisas demais para organizar, mas talvez justo por isso ele se sinta bem, feliz, povoado de planos. (TEZZA, 2011, p. 15, grifo do autor)

O narrador dá pistas na obra de que a personagem do pai pode se tratar do próprio autor, mas esse campo da dúvida põe em discussão a análise subjetiva de uma ficção, centrada na subjetividade do narrador. Hoje, com o crescente estudo do "eu", tanto na literatura quanto na vida cotidiana, fala-se muito de si, e as pessoas, por sua vez, expõem-se cada vez mais, quando se trata de experiências pessoais nos livros publicados. Cada um relata a sua vivência seletiva, e aquilo que se considera que de mais interessante há na sua vida em comparação à de outro sujeito.

Não é só na literatura que o "eu" tem ganhado força no que diz respeito ao estudo de si. Atualmente, tem crescido a curiosidade pela vida do outro e a ideia de senso comum de que: se deu certo para um, dará certo para o outro. Sobre a escrita de biografias contemporâneas e de como se está compondo o seu espaço, Arfuch (2010, p. 60) afirma que:

Efetivamente, cada vez interessa mais a (típica) biografia de notáveis e famosos ou sua "vivência" captada no instante; há um indubitável retorno do autor, que inclui não somente uma ânsia de detalhes de sua vida, mas os "bastidores" de sua criação; multiplicam-se as entrevistas "qualitativas" que vão atrás da palavra do ator social; persegue-se a confissão antropológica 
ou o testemunho do "informante-chave". Mas não apenas isso: assistimos a exercícios de "ego-história", a um auge de autobiografias intelectuais, à narração autorreferente da experiência teórica e à autobiografia como matéria da própria pesquisa, sem contar a paixão pelos diários íntimos de filósofos, poetas, cientistas, intelectuais. E, é preciso dizê-lo, às vezes não há muitas diferenças de tom entre esses exercícios de intimidade e a intrusão nas vidas célebres ou comuns com as quais nos depara diariamente a televisão.

O interesse por biografias e por programas que exponham a vida de pessoas famosas é evidente nos últimos anos. A vida privada torna-se pública, do ponto de vista de exposição pessoal do que é considerado íntimo do sujeito exposto, e cada vez mais cresce a curiosidade pelas vidas alheias, seja nas biografias escritas, nos programas de televisão e na internet (redes sociais, YouTube).

Além de tornar público o que é privado, há uma preocupação com o que será exposto. À medida em que o sujeito seleciona o que irá expor sobre sua vida, pensa também no que outros irão pensar a respeito de si e se, principalmente, terá um retorno positivo (considerando biografias, blogs, redes sociais, YouTube etc). Em se tratando da publicação de obras que visam somente o mercado, em detrimento da qualidade de leitura, Chiappini (2000, p. 23) diz que:

\begin{abstract}
A instrumentalização da literatura hoje se dá por parte dos produtores que visam sobretudo à venda, seja por parte dos leitores que, apressadamente, vinculam as obras às significações parciais e arbitrariamente postuladas, resistindo à sua sedução para muitas vezes empreender uma caça às bruxas, em leituras empobrecedoras.
\end{abstract}

As biografias de personalidades contemporâneas e a curiosidade em saber das vidas privadas reafirmam o que diz Chiappini, visto que a publicação de celebridades são as tais "leituras empobrecedoras" destacadas pela autora. Nesse sentido, há o problema da exposição e o seu incentivo, bem como a publicação de obras que não são relevantes, no âmbito literário e estético.

Em contrapartida, O filho eterno é uma obra ficcional e de relatos da experiência pessoal do autor sob uma ótica literária e estética, fazendo o contraponto entre a questão biográfica e a ficção: "Se eu escrever um livro sobre ele, ou para ele, o pai pensa, ele jamais conseguirá lê-lo" (TEZZA, 2011, p. 65). A voz do pai, em primeira pessoa ("Se eu escrever um livro sobre ele, ou para ele"), iniciando o período, e, no mesmo enunciado, o narrador, em terceira pessoa ("o pai pensa"), 
concluindo, assim, mais uma vez com a reflexão do pai ("ele jamais conseguirá lêlo").

A duplicidade de vozes no romance leva o leitor a vagar pelos pensamentos do pai, como em um monólogo da sua vida real, construída sob o ponto de vista de um narrador onisciente:

Todas as palavras que o novo pai recebeu ao longo da vida criaram nele esta escravidão consentida, esse breve mas poderoso imperativo ético que se faz em torno de tão pouca coisa: quem é a criança que está ali? O que temos em comum? O que, afinal, eu escolhi? Como conciliar a ideia fundamental de liberdade individual, que move a fantástica roda do Ocidente, ele declama, com a selvageria da natureza bruta, que por uma sucessão inextricável de acasos me trouxe agora essa criança? O próprio Rousseau abandonou os filhos, ele se lembra, divertindo-se. (TEZZA, 2011, p. 18)

Os questionamentos do pai em relação ao filho Felipe e o desafio de conviver com a síndrome de Down, da qual não sabe nada a respeito, amedrontam-no e o colocam em uma situação angustiante de responsabilidade. Ele questiona desde sua vida até o que ele tem em comum com Felipe e, por último, justifica com uma ação do filósofo Rousseau ${ }^{3}$. Ao se lembrar do abandono do filósofo em relação aos filhos, demonstra naturalidade e até se diverte: "O próprio Rousseau abandonou os filhos, ele se lembra, divertindo-se".

Bosi (2013) destaca que Rousseau foi alvo da desconfiança dos leitores, a presença da memória em Confissões mostrou seu lado memorialista e causou dúvida e suspeita, se ele estava relatando a verdade ou inventando. Outro filósofo que o narrador menciona e de quem recebe influência é Sartre, na distinção entre ficção e não-ficção. Ambos se fazem presentes no processo de escritura do pai e em sua relação com o filho: a escritura como forma de expressão da relação de paternidade.

Nesse contexto, a presença da memória como base de uma história põe em questão a sua confiabilidade, bem como afirma Gagnebin (2001) em seu artigo "Memória, história e testemunho". Por esse motivo, narrativas memorialísticas, na maioria, subjetivas, são questionadas se são fatos narrados ou inspirados em outros acontecimentos e que estão sujeitos à criatividade do autor. Exatamente pela

\footnotetext{
${ }^{3} \mathrm{Na}$ narrativa de Tezza, o autor menciona alguns filósofos que o influenciaram na vida e na escritura, e um deles é Jean-Jacques Rousseau, sobretudo sua obra autobiográfica Confissões, publicada postumamente, e que pode ser lida como um romance.
} 
memória não se tratar de algo confiável, uma vez que depende do que é lembrado, se é uma recordação corriqueira ou traumática. Considerando essa última, há um grande risco de não ser tão fiel ao que de fato ocorreu.

\title{
Os limites entre a ficção e a não-ficção
}

Narrativas que relatam experiências pessoais estão nessa linha tênue da confiabilidade ou não das informações, porque ainda há separação entre o ficcional e o não-ficcional. Nos últimos tempos, muitas narrativas com a presença de ambas têm crescido, valendo-se dos relatos pessoais para escrever ficção. Se as experiências pessoais - e fotografias - em obras literárias são motivos de questionamento, isso é fato. Nesse sentido, Bosi (2013) afirma que o escritor sabe quando está mentindo, isso vale para o indivíduo comum que expõe o que inventa/cria e o que é "real". Diante da suspeita do valor biográfico exibido, a literatura dialoga com o escritor, com a obra e com o leitor.

No campo literário, a ficção não deixa de ser ficção por se valer do "mundo real", embora a fronteira que há entre ela e a não-ficção seja arriscada, pois não é possível identificar o que faz parte da criação do autor e o que faz parte da sua experiência pessoal, como narrador e leitor. Acerca desse apontamento, Bosi (2013, p. 223, grifo do autor) aponta que:

\begin{abstract}
Falar em "fronteiras" da literatura dentro desse campo de interações é sempre recuar um pouco, é no fundo pensar as diferenças entre ficção e não-ficção. É procurar um chão sólido de conceitos pelos quais tudo o que guarda um compromisso direto com a experiência (com a experiência consensualmente verificável) é não-ficção. Mesmo que sejam memórias, mesmo que se use a primeira pessoa gramatical como sujeito da enunciação, mesmo que sejam diário, cartas, autobiografia, enfim, textos cujas formas estão às vezes próximas do que nós consideramos como literatura. Uma hipótese provável é que há realmente um momento em que a fronteira existe, por pura, por mínima que seja, por transparente que seja, como um cristal que separa dois ambientes; e a percepção da fronteira é testada pela consciência do escritor, enquanto testemunha. Ele sabe que o objeto da sua escrita é a sua experiência, e é uma experiência que ele pode atestar, empiricamente verificável: o real que aconteceu. Quando assume situar-se no plano da memória, no plano da não-ficção, ele sabe o momento que está mentindo.
\end{abstract}

Bosi (2013) é detalhista na sua explicação acerca das fronteiras da literatura, sobre o que é verdade e o que não é. Seu posicionamento deixa claro que há 
fronteira, por menor que seja, no entanto, ele se refere ao escritor, e não é esse o ponto de vista nesta análise de $O$ filho eterno. Leva-se em conta o escritor, enquanto elemento da narrativa e da análise do romance. Quando se considera a obra um romance, é importante que o narrador e o discurso direcionem a narração, não só em terceira pessoa, mas em uma distância entre o narrador e o escritor.

Se esta narração se utiliza de experiências do "eu", então manifestam-se fatos e acontecimentos "reais" do autor, mas não é determinante para ser considerada uma autobiografia, pois não há como determinar até que ponto o escritor está mentindo. Ele sabe, mas o narrador e o leitor, não. Sobre a definição de autobiografia, Lejeune (2014, p. 16) afirma que é uma "narrativa retrospectiva em prosa que uma pessoa real faz de sua própria existência, quando focaliza sua história individual, em particular a história de sua personalidade". A partir desse conceito, ele elabora os critérios para se considerar uma obra autobiográfica:

\begin{abstract}
O autor é, pois, um nome de pessoa, idêntico, que assume uma série de textos publicados diferentes. Ele extrai sua realidade da lista de suas primeiras obras, frequentemente presente no próprio livro. A autobiografia (narrativa que conta a vida do autor) pressupõe que haja identidade de nome entre o autor (cujo nome está estampado na capa), o narrador e a pessoa de quem se fala. Esse é um critério muito simples, que define, além da autobiografia, todos os outros gêneros da literatura íntima (diário, autorretrato, autoensaio). (LEJEUNE, 2014, p. 27 - 28, grifo do autor)
\end{abstract}

Na obra de Tezza, a personagem central não tem nome, bem como o narrador, não há indicativo de diálogo, a voz do pai é evidenciada no meio do discurso, sem a distinção de quem é o personagem e quem é o narrador. E esse é também um ponto de dúvida do leitor. Para o teórico da autobiografia, $O$ filho eterno não é considerado uma obra autobiográfica porque autor e personagem não têm o mesmo nome, mas ainda há uma subjetividade dissimulada, por não revelar a identidade do pai, apenas a de Felipe.

O fato de o autor e a personagem não terem o mesmo nome é um dos critérios selecionados por Lejeune (2014, p. 30) para não caracterizar uma obra como autobiográfica: "O pacto autobiográfico é a afirmação, no texto, dessa identidade, remetendo, em última instância, ao nome do autor, escrito na capa do livro". Outro ponto a ser destacado na obra de Tezza, como ficção, em relação à autobiografia, é a questão da fidelidade da obra. Enquanto que Bosi (2013) afirma 
haver uma fronteira entre a ficção e a não-ficção, por menor que seja, ainda é complexo determinar esse limite.

A propósito, além da complexidade do estudo da subjetividade, há o fator "mundo real" como fonte de inspiração do imaginário. É possível, e muito recorrente, que um autor utilize a sua experiência pessoal em sua criação literária, e isso ainda não vai definir que se trate de uma autobiografia. Nota-se que determinado autor escreve acerca de um momento de sua vida, mas altera os nomes das personagens, das ruas da cidade em que a história é ambientada e faz adaptações para que sua "criação" tenha um novo olhar. Baseado nisso: Como um leitor vai definir essa história como ficcional ou não-ficcional? E qual o limite do que é verdade e do que é inventado? Essa problemática põe em questão as fronteiras entre ficção e história ou, ainda, entre ficção e autobiografia.

Todo indivíduo tem sua história particular, e a autobiografia, por sua vez, tem relação com as memórias desse sujeito, bem como de sua consciência. Para tanto, a escrita de biografias faz referência às memórias de um indivíduo, seja ele o autor, o narrador ou a personagem. Ao passo que a narrativa de Tezza progride, o pai alimenta suas memórias da juventude, paralelas ao seu presente com Felipe. A voz predominante na obra é a do narrador em terceira pessoa, irrompendo na narrativa a primeira pessoa, apoiando-se na consciência do pai:

\footnotetext{
Eu não posso ser destruído pela literatura; eu também não posso ser destruído pelo meu filho - eu tenho um limite: fazer, benfeito, o que posso e sei fazer, na minha medida. Sem pensar, pega a criança no colo, que se larga saborosamente sobre o pai, abraçando-lhe o pescoço, e assim sobem as escadas até a porta de casa. (TEZZA, 2011, p. 138)
}

O recurso linguístico utilizado pelo narrador demonstra que se trata de confissões do pai, quando utiliza a primeira pessoa, no primeiro período. Há também a presença do narrador, no segundo período, na terceira pessoa, descrevendo as ações das personagens, pai e filho. Essa duplicidade de discurso acusa a dissimulação do escritor em expressar-se como o pai e como o narrador. No mesmo parágrafo, nota-se a presença dos dois discursos em busca das confissões do pai de Felipe. O narrador tem como referência Rousseau e Sartre, com suas obras sobre experiências pessoais, um outro elemento que constitui características subjetivas do autor no romance, bem como o seu caráter ficcional na narrativa. 
O filho eterno está no campo da ficção, na construção de um mundo ficcional que se vale do "mundo real" como fonte primeira de inspiração, mas que, ao configurá-lo através da linguagem, transcende-o, transforma-o. Por meio da linguagem, é possível notar quando o narrador se posiciona como personagem na obra e quando se distancia, fazendo apenas o papel de narrador. E não se trata apenas do discurso, mas como a duplicidade de vozes em um mesmo período ou parágrafo põe em questão quem é esse pai e em que momento e ambiente ele se encontra.

Isso é decorrente da linguagem fragmentada, por isso não é tão simples entender em que momento e ambiente o pai se encontra enquanto o romance é narrado. Um ponto interessante da narrativa é que a personagem do pai não se revela durante o romance, se é o narrador ou não, porém permanece a dissimulação na linguagem. Para a crítica Victoria Saramago (2013), o caráter ficcional da narrativa, por meio da dualidade do discurso entre narrador e personagem, faz com que a personagem do pai observe a si próprio sem sair dele. A releitura que faz de si mesmo em suas reflexões e consciência o posiciona como paciente e analista na história. De maneira impiedosa, faz críticas a seu comportamento sem esperar que outro o faça, assim como faz ao filho, interiormente, em seus pensamentos.

A visão por detrás do narrador simula esse comportamento, lembrando que, na obra, o leitor também é colocado nessa posição de analista do texto, em alguns trechos de diálogo do narrador com o leitor, fazendo uso, implicitamente, de imperativos. Caracterizando o sujeito pai como biográfico no romance $O$ filho eterno, abre-se uma brecha para considerar a obra um romance autobiográfico, definido por Lejeune (2014, p. 29, grifo do autor):

\footnotetext{
Esses textos entrariam na categoria do "romance autobiográfico". Chamo assim todos os textos de ficção em que o leitor pode ter razões de suspeitar, a partir das semelhanças que acredita ver, que haja identidade entre autor e personagem, mas que o autor escolheu negar essa identidade ou, pelo menos, não afirmá-la. Assim definido, o romance autobiográfico engloba tanto narrativas em primeira pessoa (identidade do narrador e do personagem) quanto narrativas "impessoais" (personagens designados em terceira pessoa); ele se define por seu conteúdo. À diferença da autobiografia, ele comporta graus. A "semelhança" suposta pelo leitor pode variar de um vago "ar de família" entre o personagem e o autor até uma quase transparência que leva a dizer que aquele é o autor "cuspido e escarrado".
} 
As características mencionadas por Lejeune (2014) acerca dessa categoria, "romance autobiográfico", abrem espaço para o romance tezziano ser nela inserido. No entanto, o leitor ainda tem "razões de suspeitar" que o texto de ficção é também autobiográfico. Dessa maneira, as semelhanças entre autor e personagem são percebidas a partir do momento em que o leitor conhece a vida do autor, assiste a entrevistas e investiga sobre ele. Quando a obra é caracterizada como romance na própria capa e quando há distanciamento do autor na linguagem e na história, de alguma maneira, também abre espaço para ser analisada como tal.

Como ficção, $O$ filho eterno não apresenta o nome do pai para não haver coincidência nominal com o autor, mas deixa a dúvida para o leitor. A escolha do discurso em terceira pessoa, na grande maioria das vezes, também faz dela uma narrativa impessoal, além da própria caracterização do autor na capa como um romance. Apesar de haver mais evidências ou suspeitas de se tratar de uma autobiografia, a narrativa tezziana não exclui o fato de ser ficção.

Eis aí o cerne da questão: existe uma dualidade entre ficção e não-ficção na obra, e esse movimento pendular faz do leitor o grande responsável por desvendar (ou não) a posição em que quer analisá-la. Se é uma obra sobre a vida do autor é uma dúvida que o persegue em toda a narrativa e o faz questionar até a "veracidade" dos relatos do narrador. Dessa forma, esse narrador, elemento da construção artística da obra, faz parte das suspeitas do leitor quanto à verossimilhança do relato, mas o fato de ser fidedigno ou não, na verdade, não é primordial na discussão em questão.

Segundo Arfuch (2010), o importante é que o narrador é outro, diferente daquele que protagoniza a história, mesmo que seja uma obra sobre as experiências pessoais do autor, pois aquele é fruto da construção da narrativa. Sobre a relação entre autor e personagem na obra:

não há identidade possível entre autor e personagem, nem mesmo na autobiografia, porque não existe coincidência entre a experiência vivencial e a "totalidade artística". Essa postura assinala, em primeiro lugar, o estranhamento do enunciador a respeito de sua "própria" história; em segundo lugar, coloca o problema da temporalidade como um desacordo entre enunciação e história, que trabalha inclusive nos procedimentos de autorrepresentação. Não se tratará então de adequação, da "reprodução" de um passado, da captação "fiel" de acontecimentos ou vivências, nem das transformações "na vida" sofridas pelo personagem em questão, mesmo quando ambos - autor e personagem - compartilharem o mesmo contexto. Tratar-se-á, simplesmente, de literatura: essa volta de si, esse estranhamento do autobiógrafo, não difere em grande medida da posição 
do narrador diante de qualquer matéria artística e, sobretudo, não difere radicalmente dessa outra figura, complementar, a do biógrafo - um outro ou "um outro eu", não há diferença substancial -, que, para contar a vida de seu herói, realiza um processo de identificação e, consequentemente, de valoração. (ARFUCH, 2010, p. 55, grifo do autor)

Narrador e personagem podem estar inseridos no mesmo contexto de vivência, mas trata-se de literatura, mesmo quando há coincidência de experiência de vida entre ambos. A partir do momento em que um autor cria o narrador para contar determinada história, ele representa por meio daquele elemento da narrativa a sua criação artística, por isso ele destaca, logo no início, que 'não existe coincidência entre a experiência vivencial e a "totalidade artística"'.

Arfuch (2010) indica que não se trata de coincidência entre autor e personagem, ainda que estejam no mesmo contexto. Vale destacar essa afirmação, visto que um romance sobre experiências e histórias do autor não o define como autobiográfico. Se o mesmo for escrito como ficção, por menor que seja, há uma fronteira entre ficção e não-ficção. Outro ponto dessa problemática é que a obra aqui analisada, $O$ filho eterno, permite ao leitor a sua análise como romance e como autobiografia, pois não há um elemento que a defina como uma ou outra, visto que nela há elementos ficcionais e não-ficcionais.

\section{Considerações finais}

A "desordem" existente entre história, ficção e biografia na obra $O$ filho eterno foi crucial para a nossa abordagem aqui discutida. É válido considerar que a presença da subjetividade na ficção separou as obras contemporâneas em ficcionais ou autobiográficas, tratando-se de experiências pessoais que, pelo menos, coincidam com as do autor. O preço a ser pago por isso é a incansável busca por respostas sobre os limites da ficção.

Nesse sentido, na busca por possíveis respostas, este trabalho tem como fio condutor a subjetividade e as memórias da personagem pai, contribuindo, assim, para o debate acerca da ficção e da história. A suspeita pela identidade do narrador e/ou pai prossegue em toda a narrativa, por isso é um movimento pendular, confuso e inquietante. Qualquer determinação sobre a voz do pai ser a mesma do autor é arriscada, mas o fato é que a análise da obra é feita a partir de sua ficcionalidade, 
não a considerando autobiográfica, ainda que a crítica insista em considerar tal hipótese.

Para tanto, os motivos pelos quais ela é analisada como romance estão no distanciamento do autor, pois não há revelação do nome do pai no enredo, colocando em dúvida a hipótese de que é o pai o autor da história, assim como sua definição como romance e a duplicidade do discurso, entre narrador e pai, em um mesmo período no texto.

O uso das experiências pessoais do autor na ficção mostra que não há como determinar a fronteira do que é criação e do que é vivência. A construção ficcional a partir das memórias e, consequentemente, da consciência do autor/narrador/pai não são exclusivas para considerar uma autobiografia, pois se valem do "mundo real" até certo ponto. Um limite (im)possível de decifrar como verdade ou mentira, mas as suspeitas levantadas pela crítica de que é "brutalmente autobiográfico" (SARAMAGO, 2013) não são capazes de delimitar essa fronteira, se o autor está se valendo das experiências pessoais ou não.

Concluímos que, diante da narração de experiências pessoais, é importante lembrar que o narrador está no campo da ficcionalidade, e a história é o ponto de partida de sua inspiração. Não é a própria história a criação do autor, mas ele se vale dela para a escrita da obra.

\section{Referências bibliográficas}

ARFUCH, Leonor. O espaço biográfico: dilemas da subjetividade contemporânea. Tradução: Paloma Vidal. Rio de Janeiro: EdUERJ, 2010.

BOSI, Alfredo. As fronteiras da literatura. In; BOSI, Alfredo. Entre a literatura e a história. São Paulo: Editora 34, 2013, p. 221 - 234.

CHIAPPINI, Ligia. Literatura e História. Notas sobre as relações entre os estudos literários e os estudos historiográficos. In: Literatura e Sociedade. São Paulo, ํㅡ 5, 2000, p. 18 - 28.

GAGNEBIN, Jeanne Marie. História, memória, testemunho (2001b). In: BRESCIANI, Stella; NAXARA, Márcia. Memória e (res) sentimento - indagações sobre uma questão sensível. Campinas: UNICAMP, 2001, p. 85-94.

LEJEUNE, Philippe. O pacto autobiográfico: de Rousseau à internet. Tradução: Jovita Maria Gerheim Noronha, Maria Inês Coimbra Guedes. 2. ed. Belo Horizonte: Editora UFMG, 2014. 
SARAMAGO, Victoria. O filho eterno, o duplo do pai: o filho e a ficção de Cristovão Tezza. São Paulo: É Realizações, 2013.

TEZZA, Cristovão. O filho eterno. Rio de Janeiro: Saraiva, 2011.

TEZZA, Cristovão. Biografia. Disponível em:

<http://www.cristovaotezza.com.br/p_biografia.htm> Acesso em: agosto de 2017. 